\title{
Prevalence of dental caries among five-year-old school children in Shimla city, Himachal Pradesh
}

\author{
Vinay Kumar Bhardwaj, S. Vaid ${ }^{1}$, A. Chug ${ }^{2}$, P. Jhingta ${ }^{3}$, N. Negi ${ }^{1}$, D. Sharma ${ }^{3}$ \\ Department of Public Health Dentistry, ${ }^{1}$ Orthodontics and Dentofacial Orthopaedics, ${ }^{2}$ Oral and \\ Maxillofacial Surgery, ${ }^{3}$ Periodontology, H. P. Government Dental College and Hospital, Shimla, \\ Himachal Pradesh, India
}

\author{
Address for correspondence: \\ Dr. Vinay Kumar Bhardwaj, \\ Department of Public Health Dentistry, \\ H. P. Government Dental College \\ and Hospital, Shimla, \\ Himachal Pradesh - 171001, India. \\ E-mail:dr.viney@gmail.com
}

\begin{abstract}
Objective: The purpose of the study was to assess the prevalence of dental caries among five year old school children in Shimla city-Himachal Pradesh. Materials and Methods: The sample consisted of 800 school going children 421 (52.62\%) boys and 379 (47.38\%) girls from government primary schools which were selected randomly from four different zones of Shimla city. Type -III examination was conducted. The data obtained was analyzed by SPSS version 15 ( Inc., Chicago) using proportion test for comparison. Results: Boys were having higher caries prevalence than girls, (46.8\% vs 41.6\%) and the difference was statistically significant $(P<0.05)$. Caries prevalence was higher in the mandibular arch than in the maxillary arch among both the gender with a difference which was significant statistically. Caries prevalence was higher on left than right side in both male and female subjects. When the caries prevalence of the anterior teeth was compared between the gender, boys showed higher caries prevalence than girls and this difference was statistically significant $(P<0.05)$. Comparison of caries between the arches in the anterior segment revealed that caries attack was higher in the maxillary arch and the difference was highly significant statistically $(P<0.01)$. Conclusion: Dental caries is a significant public health problem among this population. It is a cause of concern which point out to the utmost necessity of dental health education of children, school teachers and parents. Emphasis should be given on regular check-up and application of preventive measures and treatment modalities.
\end{abstract}

Key words

Dental caries, prevalence, school children, Shimla

\section{INTRODUCTION}

Oral health is an integral part of general health. ${ }^{[1]}$ Healthy mouth enables an individual to eat, speak, and socialize without active disease or discomfort and contributes to the general well-being. It is concerned with maintaining the health of craniofacial complex, the teeth, and gums as well as the tissue of the face and head that surrounds the mouth. ${ }^{[2]}$ Dental caries because of its ubiquitous nature remains one of the most prevalent afflictions of mankind since the dawn of time. ${ }^{[3]}$ This disease can aptly be termed as a scourge of modern civilization and no nation or continent has escaped the ill effects of this deadly malady. It is a product of civilization, which increases with

\begin{tabular}{|l|l|}
\hline \multicolumn{2}{|c|}{ Access this article online } \\
\hline Quick Response Code: & Website: \\
\hline & www.ejgd.org \\
\hline & \\
\hline
\end{tabular}

increase in standard of living and nutritional habits. ${ }^{[4]}$ Dental caries not only causes damage to the tooth, but is also responsible for several morbid conditions of the oral cavity and other systems of the body. ${ }^{[5]}$ The prevalence pattern of dental caries not only varies with age, sex, socio-economic status, race, geographical location, food habits and oral hygiene practices but also within the oral cavity. ${ }^{[6]}$ All the teeth and all the surfaces are not equally susceptible to caries. It is of interest, therefore, to know the relative caries susceptibility of the teeth in the maxilla and mandible. ${ }^{[4]}$ No data is available, which gives us a view of the prevalence of dental caries in school children in Shimla city. Hence, this study has been taken to assess the prevalence of dental caries among five-year-old school children in Shimla city- Himachal Pradesh in India.

\section{MATERIALS AND METHODS}

This study is the first of its kind on this group of population and was carried out on five-year-old school children of Shimla city for the assessment of dental caries prevalence and its pattern in primary dentition. Sample frame was school children aged five years in government schools in 
Shimla city, capital of Himachal Pradesh. The study was conducted on a study sample of 800 school-going children (421 boys and 379 girls) over a time span of three months (March to May 2008). Whole Shimla city was divided into four zones, and 200 subjects from each zone were selected for the examination. Purpose of the study was explained to the school authorities, and official permission was sought from the director elementary education, district education officer, and administrative heads of the concerned school. Written consent from the parents of these children was taken prior to the study. This study was cleared by the institutional research ethical committee.

\section{Inclusion criteria}

School children aged five years who were present on the day of examination and had got consent from their parents for the same were included in the study.

\section{Exclusion criteria}

Children less than five year of age, or five-year-old children who did not got consent from their parents and who were absent on the day of examination.

Type-III examination as recommended by American Dental Association was conducted, ${ }^{[1]}$ which include use of mouth mirror and probe and examination in the natural daylight. Children were examined in the school premises in suitable places with the subjects seated in ordinary chairs. The data were collected by single examiner as per prescheduled time in the school. The data was entered in the format by experienced intern who was well-versed with the medical technical terms. Intern was seated close enough to the examiners so that the instructions and codes could be easily heard and the examiners could verify the correct entry of the findings.

To ensure the reliability and validity of the results, the examiner was first calibrated against an experienced teacher, obtaining a 0.85 kappa index and a percentage agreement of $98.9 \%$ for dentition status. Also, to ensure consistency throughout the study, a random $10 \%$ of the sample was re-examined and the intraobserver agreement was calculated; the percentage agreement was 99\% and the kappa index was 0.89 for the same status. 25-30 school children were examined daily by the examiner himself in the school premises. Health education was given to the children after each examination session. Referral cards were given to the children who needed treatment, to visit dental college and hospital along with parents for treatment on priority.

The data obtained was entered in the computer and analyzed using SPSS (Statistical package for Social Sciences) version 15 (Inc., Chicago), using proportion test for comparison of caries prevalence among the different groups: Gender, arch, teeth (anterior and posterior) and right and left side of the oral cavity. $P$ value of $\leq 0.05$ and $\leq 0.01$ was considered as statistically significant and highly significant, respectively.

\section{RESULTS}

The study population consisted of 800 school children of the age of 5 years, which included 421 (52.5\%) boys and $379(47.5 \%)$ girls.

Table 1 shows prevalence of dental caries among study population. Caries prevalence was $44.3 \%$. Gender-wise comparison revealed that caries prevalence was higher in boys $(46.8 \%)$ than in girls $(41.6 \%)$ and the difference was statistically significant $(P<0.05)$.

Table 2 shows prevalence of dental caries in the arches. Caries prevalence was $26.45 \%$ in the maxillary arch and $36.1 \%$ in the mandibular arch. Among boys, the mandibular arch showed a higher caries level (37.3\%) than the maxillary arch (31.6\%) and the difference was statistically significant $(P<0.05)$. Similarly, among girls, the mandibular arch showed higher caries prevalence $(35.1 \%)$ than the maxillary arch $(21.3 \%)$ and the difference was statistically highly significant $(P<0.01)$.

Table 3 shows dental caries prevalence on right and left side of oral cavity. On comparing the right and left side of oral cavity, it was found that caries occurred in a bilateral pattern (right side $=36.5 \%$, left side $=38.85 \%$ ). Among boys, caries prevalence was $37.9 \%$ and $40.2 \%$ for right and left sides, respectively. Among girls, caries prevalence was $35.2 \%$ and $37.5 \%$ for right and left side, respectively, and the difference was not significant.

Table 4 represents tooth-wise and gender-wise prevalence of dental caries. In both the gender, when caries prevalence

\begin{tabular}{|c|c|c|c|}
\hline \multicolumn{4}{|c|}{ Subjects $($ Age $=5$ years $)$} \\
\hline \multirow[t]{2}{*}{ Gender } & \multirow[t]{2}{*}{ Examined } & \multicolumn{2}{|c|}{ Affected } \\
\hline & & $N *$ & $\%$ \\
\hline Boys & 421 & 197 & $46.8 \#$ \\
\hline Girls & 379 & 158 & 41.6\# \\
\hline Total & 800 & 355 & $44 \cdot 3$ \\
\hline
\end{tabular}

$*=$ Number of subjects, $\# Z=2.04, P<0.05$

\begin{tabular}{|c|c|c|c|c|c|}
\hline \multirow[t]{2}{*}{ Gender } & \multirow[t]{2}{*}{$\begin{array}{l}\text { Subjects } \\
\text { examined }\end{array}$} & \multicolumn{2}{|c|}{$\begin{array}{l}\text { Maxillary arch } \\
\text { affected }\end{array}$} & \multicolumn{2}{|c|}{$\begin{array}{l}\text { Mandibular } \\
\text { arch affected }\end{array}$} \\
\hline & & $\mathrm{N} *$ & $\%$ & $\mathrm{~N} *$ & $\%$ \\
\hline Boys & 421 & 133 & $31.6 * *$ & 157 & $37.3^{* *}$ \\
\hline Girls & 379 & 81 & $21.3 \#$ & 132 & $35.1 \#$ \\
\hline Total & 800 & 214 & 26.45 & 289 & 36.1 \\
\hline
\end{tabular}


was compared between the anterior and the posterior teeth, it was higher in the posterior segment than in the anterior segment and the difference was highly significant statistically $(P<0.01)$. When the caries prevalence of the anterior teeth was compared between the gender, boys showed higher caries prevalence than girls and statistically this difference was highly significant $(P<0.01)$.

Table 5 shows tooth-wise and arch-wise prevalence of dental caries. In both the arches, caries occurred more frequently in the posterior teeth. Comparison of caries between the arches in the anterior segment revealed that caries attack was higher in the maxillary arch and the difference was statistically highly significant $(P<0.01)$. On the other hand, comparison of caries prevalence was higher in the mandibular arch than in maxillary arch. The difference was highly significant.

\section{DISCUSSION}

Present study has revealed prevalence of dental caries

\begin{tabular}{|c|c|c|c|c|c|}
\hline \multicolumn{6}{|c|}{$\begin{array}{l}\text { Table 3: Showing prevalence of dental caries on right } \\
\text { and left side of the oral cavity }\end{array}$} \\
\hline \multirow[t]{2}{*}{ Gender } & \multirow[t]{2}{*}{$\begin{array}{l}\text { Subjects } \\
\text { examined }\end{array}$} & \multicolumn{2}{|c|}{$\begin{array}{l}\text { Right side } \\
\text { affected }\end{array}$} & \multicolumn{2}{|c|}{$\begin{array}{l}\text { Left side } \\
\text { affected }\end{array}$} \\
\hline & & $\mathrm{N}^{*}$ & $\%$ & $\mathrm{~N} *$ & $\%$ \\
\hline Boys & 421 & 159 & $37.9 * *$ & 169 & $40.2 * *$ \\
\hline Girls & 379 & 133 & $35.2 \#$ & 142 & $37.5 \#$ \\
\hline Total & 800 & 292 & 36.5 & 311 & 38.85 \\
\hline
\end{tabular}

and its pattern among five-year-old government school children in Shimla city. Among the study population, caries was significantly more prevalent in boys than in girls, which suggest that dental caries show some predilection for gender. These findings were consistent with those of Peter, ${ }^{[7]}$ Zerfowski et al, ${ }^{[8]}$ and Sarvanan et al. ${ }^{[9]}$ This higher caries prevalence in boys in primary dentition may be due to early eruption and longer retention of these teeth among boys Graves RC et al. ${ }^{[10]}$ Prevalence pattern of dental caries shows some relation to the arches and the mandibular arch is affected more often than the maxillary arch as reported by Sathe..$^{[1]}$

In the present study, interarch comparison revealed that caries prevalence was higher in mandibular arch and it was statistically significant in both the gender. Tewari A et $a l^{[12]}$ and Jawadekar et $a l^{[13]}$ had reported similar findings. However, Healey and Cheyne ${ }^{[14]}$ reported higher caries prevalence in the maxillary arch.

Comparison of caries prevalence in relation to right and left side of the oral cavity revealed that dental caries occurs predominantly as a bilateral phenomenon. Similar observation was reported by Finn ${ }^{[15]}$ and Dunning. ${ }^{[1]}$ Results of the present study revealed that caries prevalence was higher in posterior teeth as compared to anterior teeth in both the gender, similar to the findings observed by Peter, Gillespie ${ }^{[7]}$ and Chawla et al. ${ }^{[16]}$ This could be due to the complex morphological structure of the posterior teeth. ${ }^{[1,17,18]}$ In the present study, among the posterior teeth, primary first molars in both the arches

\begin{tabular}{|c|c|c|c|c|c|c|c|c|c|}
\hline \multirow[t]{3}{*}{ Type of tooth } & \multicolumn{3}{|c|}{ Boys teeth } & \multicolumn{3}{|c|}{ Girls teeth } & \multicolumn{3}{|c|}{ Total } \\
\hline & \multirow[t]{2}{*}{ Examined } & \multicolumn{2}{|c|}{ Affected } & \multirow[t]{2}{*}{ Examined } & \multicolumn{2}{|c|}{ Affected } & \multirow[t]{2}{*}{ Examined } & \multicolumn{2}{|c|}{ Affected } \\
\hline & & $N *$ & $\%$ & & $N *$ & $\%$ & & $\mathrm{N*}$ & $\%$ \\
\hline Central incisor** & 1628 & 147 & 9 & 1524 & 56 & 3.6 & 3152 & 203 & 6.44 \\
\hline Lateral incisor** & 1652 & 64 & 3.9 & 1528 & 29 & 1.9 & 3180 & 93 & 2.92 \\
\hline Canine** & 1656 & 31 & 1.9 & 1526 & 28 & 1.8 & 3182 & 59 & 1.85 \\
\hline $1^{\text {st }}$ molar\# & 1651 & 295 & 17.9 & 1519 & 204 & 13.4 & 3170 & 499 & 15.74 \\
\hline $2^{\text {nd }}$ molar\# & 1632 & 297 & 18.2 & 1522 & 258 & 17 & 3154 & 555 & 17.59 \\
\hline
\end{tabular}

\begin{tabular}{|c|c|c|c|c|c|c|}
\hline \multirow[t]{3}{*}{ Type of tooth } & \multicolumn{3}{|c|}{ Maxillary arch teeth } & \multicolumn{3}{|c|}{ Mandibular arch teeth } \\
\hline & \multirow[t]{2}{*}{ Examined } & \multicolumn{2}{|c|}{ Affected } & \multirow[t]{2}{*}{ Examined } & \multicolumn{2}{|c|}{ Affected } \\
\hline & & $N *$ & $\%$ & & $N *$ & $\%$ \\
\hline Central incisor** & 1600 & 194 & 12.1 & 1552 & 9 & 0.57 \\
\hline Lateral incisor** & 1620 & 89 & $5 \cdot 5$ & 1560 & 4 & 0.26 \\
\hline Canine** & 1628 & 45 & 2.8 & 1554 & 14 & 0.9 \\
\hline $1^{\text {st }}$ molar\# & 1632 & 182 & 11.15 & 1538 & 317 & 20.6 \\
\hline $2^{\text {nd }}$ molar\# & 1626 & 205 & 12.6 & 1528 & 350 & 22.9 \\
\hline
\end{tabular}


are less susceptible to caries than the primary second molars, even though the former erupts at an earlier age. This difference in individual tooth susceptibility is due to the fissure topography of molars. The pits and fissures in second primary molars are deeper and less completely coalesced. ${ }^{[15]}$ This suggests that in primary dentition, the second molar is the tooth with highest caries experience among five-year-old children.

It is also evident that the sequence of caries attack follows a specific pattern i.e. Mandibular molars, maxillary molars, and maxillary anterior teeth were predominantly affected by caries, whereas the mandibular anterior teeth were least affected. This is similar to the caries pattern described by Chawla et $a l^{[16]}$ In the present study, the mandibular incisors are unaffected, which resembles the early childhood caries pattern where the maxillary primary incisors, maxillary and mandibular primary molar are affected, sparing mandibular primary incisors. ${ }^{[16,19,20]}$ The protection by the tongue and the opening of major salivary ducts near the lower incisors has been advocated as a reason for this resistance to caries. It was also evident that caries attack was higher in the lower arch than in the upper arch in the posterior teeth. Chawla et al, ${ }^{[16]}$ Sarkar, and Chowdhary ${ }^{[21]}$ reported similar findings in their studies.

\section{SUMMARY AND CONCLUSION}

The prevalence of dental caries in primary dentition was higher in the boys than in the girls $(P<0.05)$, higher in the mandibular arch in both the sexes (boys $P<0.05$, girls $P<0.01$ ) and shows a bilateral phenomenon in both the gender. Prevalence of dental caries was higher in posterior teeth in both the gender and in both the arches, higher in the boys than in the girls among posterior teeth $(P<0.01)$. Primary second molars had higher prevalence of dental caries than the primary first molars in both the gender and both the arches. A specific pattern of prevailing dental caries among study population was: Mandibular molars (21.7\%), maxillary molars $(10.1 \%)$, and maxillary anterior teeth $(6.5 \%)$ were predominantly affected, whereas the mandibular anterior teeth were least affected (0.4\%). Prevalence of dental caries was higher in the maxillary arch than in the mandibular arch among the anterior teeth. It was higher in the mandibular arch than the in maxillary arch among the posterior teeth and the difference was statistically highly significant $(P<0.01)$. As most of the decay in the study population can be treated with simple one-surface fillings, the Atraumatic Restorative Treatment (ART) approach seems very appropriate. Combining ART with other preventive measures will definitely improve the oral health status of most children in the present study area.

It is prudent suggestion that a greater degree of awareness should be created among parents and teachers by dentist and health educators. School authorities should organize dental checkup camps in their schools. They should follow-up students affected by dental diseases and persuade them to avail dental treatment.

\section{LIMITATIONS AND SUGGESTION}

This study was conducted on a smaller sample and without taking into effect of different variables, which affect prevalence and progression of dental caries among children. Further study should be conducted in future to know the prevalence of dental caries and its association with different variables like fluoride content of the drinking water, consumption of in between meal sugars, method of cleansing and the material used for this purpose, education of mother, socio-economic status of the parents and visit to dentist.

\section{REFERENCES}

1. Dunning JM. Principles of Dental Public Health. $4^{\text {th }}$ ed. United States: Harvard University Press; 1986. p. 338-9.

2. Yewe- Dyer M. The definition of oral health. Br Dent $J$ 1993;174:224-5.

3. Almoudi N, Salako N, Massoud I. Caries experience of children aged 6-9 years in Jeddah, Saudi Arabia. Int J Paediatr Dent 1996;6:101-5.

4. Aleksejuniene J. Caries experience and oral hygiene in Lithuanian children and adolescents. Acta Odontol Scand 1996;54:75-8.

5. Chakraborty M, Saha JB, Bhattacharya RN. Epidemiological correlates of dental caries in an urban slum of West Bengal. Indian J Public Health 1997;41:56-60.

6. World Health Organization. Oral health surveys - Basic methods. $4^{\text {th }}$ ed. Geneva: WHO; 1997.

7. Peter FI, George MG. Dental caries experience in the deciduous dentition of rural Guatemalan children aged 6 months to 7 years. J Dent Res 1976;55:951-7.

8. Zerfowski M, Koch ML, Niekusb U. Caries prevalence and treatment needs of 7 to 10 - year-old school children in South Western Germany. Community Dent Oral Epidemiol 1997;25:348-51.

9. Saravanan S, Madivanan I, Subashini B. Prevalence pattern of dental caries in the primary dentition among school children. Indian J Dent Res 2005;16:140-6.

10. Graves RC, Bohannan HM, Disney JA. Recent dental caries and treatment patterns in U.S. Children. J Public Health Dent 1986;46:23-9.

11. Sathe PV. A textbook of Community Dentistry. $1^{\text {st }}$ ed. Hyderabad: Paras Medical Publisher; 1998. p. 84-94.

12. Tewari A, Chawla HS. A study of prevalence of dental caries in an urban area of India - Chandigarh. J Indian Dent Assoc 1977;49:231-7.

13. Jawadekar SL, Dandare MP, Maya N. Dental caries susceptibility pattern. J Indian Dent Assoc 1989;60:200-3.

14. Peter S. Essentials of Preventive and Community Dentistry. $1^{\text {st }}$ ed. New Delhi: Arya (Medi) Publishing House; 1999. p. 137-9.

15. Finn SB. Clinical Pedodontics. $4^{\text {th }}$ ed. Philadephia: WB Saunders Company; 1991. p. 454-74.

16. Chawla HS, Gauba K, Goyal A. Trends of dental caries in children 
of Chandigarh over the last sixteen years. J Indian Soc Pedo Prev Dent 2000; 18:41-5.

17. Pandit IK, Singh M, Srivastava N. Prevalence of dental caries in mixed dentition period amongst children of Yamuna Nagar District (Haryana). J Indian Dent Assoc 2000;71:23-4.

18. Mc Donald RE, Avery DR. Dentistry for the child and the adolescent. $7^{\text {th }}$ ed. United States: Mosby Co; 2000 .p. 212-9.

19. Damle SG. Pediatric Dentistry. $1^{\text {st }}$ ed. New Delhi: Arya (Medi) Publishing House; 2000.p. 34-52.
20. Tandon S. Textbook of pedodontics. $1^{\text {st }}$ ed. Hyderabad: Paras-Medical Publisher; 2001. p. 178-209.

21. Sarkar S, Chowdhury KS. Incidence of caries on various surfaces of deciduous teeth. J Indian Dent Assoc 1992;63:421-5.

How to cite this article: Bhardwaj VK, Vaid S, Chug A, Jhingta P, Negi N, Sharma D. Prevalence of dental caries among five-year-old school children in Shimla city, Himachal Pradesh. Eur J Gen Dent 2012;1:34-8. Source of Support: Nil, Conflict of Interest: None declared.

\section{New features on the journal's website}

\section{Optimized content for mobile and hand-held devices}

HTML pages have been optimized of mobile and other hand-held devices (such as iPad, Kindle, iPod) for faster browsing speed.

Click on [Mobile Full text] from Table of Contents page.

This is simple HTML version for faster download on mobiles (if viewed on desktop, it will be automatically redirected to full HTML version)

\section{E-Pub for hand-held devices}

EPUB is an open e-book standard recommended by The International Digital Publishing Forum which is designed for reflowable content i.e. the text display can be optimized for a particular display device.

Click on [EPub] from Table of Contents page.

There are various e-Pub readers such as for Windows: Digital Editions, OS X: Calibre/Bookworm, iPhone/iPod Touch/iPad: Stanza, and Linux: Calibre/Bookworm.

\section{E-Book for desktop}

One can also see the entire issue as printed here in a 'flip book' version on desktops.

Links are available from Current Issue as well as Archives pages.

Click on 1 View as eBook 